\title{
Activation of ER stress by hydrogen peroxide in C2C12 myotubes
}

\author{
Nicolas Pierre ${ }^{a}$, Caroline Barbé ${ }^{a}$, Hélène Gilson ${ }^{a}$, Louise Deldicque ${ }^{b}$, Jean-Marc Raymackers ${ }^{a}$, \\ Marc Francaux ${ }^{a}$,* \\ ${ }^{a}$ Institute of Neuroscience, Université catholique de Louvain, Louvain-la-Neuve, Belgium \\ ${ }^{\mathrm{b}}$ Department of Kinesiology, Exercise Physiology Research Group, KU Leuven, Belgium
}

\section{A R T I C L E I N F O}

Article history:

Received 27 May 2014

Available online 8 June 2014

\section{Keywords:}

Unfolded protein response (UPR)

Oxidative stress

Binding immunoglobulin protein (BiP)

Activating transcription factor 6 (ATF6)

$\mathrm{X}$-box binding protein 1 spliced (XBP1s)

Eukaryotic translation-initiation factor $2 \alpha$ $(\mathrm{eIF} 2 \alpha)$

\begin{abstract}
A B S T R A C T
The purpose of this study was to examine the link between oxidative stress and endoplasmic reticulum (ER) stress in myogenic cells. $\mathrm{C} 2 \mathrm{C} 12$ myotubes were incubated with hydrogen peroxide $\left(\mathrm{H}_{2} \mathrm{O}_{2}, 200 \mu \mathrm{M}\right)$ and harvested $4 \mathrm{~h}$ or $17 \mathrm{~h}$ after the induction of this oxidative stress. A massive upregulation of binding immunoglobulin protein (BiP) was found, indicating the presence of ER stress. Nevertheless, the three branches of the unfolded protein response (UPR) were not activated to the same extent. The doublestranded RNA-dependent protein kinase (PKR)-like ER kinase (PERK) branch was the most activated as shown by the increase of phospho-eukaryotic translation-initiation factor $2 \alpha$ (eIF2 $\alpha$, Ser51) and the mRNA levels of activating transcription factor 4 (ATF4), C/EBP homologous (CHOP) and tribbles homolog 3 (TRB3). The slight increase in the spliced form of X-box binding protein 1 (XBP1s) together with the decrease of the unspliced form (XBP1 $\mathrm{u}$ ) indicated a higher endoribonuclease activity of inositol-requiring $1 \alpha($ IRE1 $\alpha)$. The transcriptional activity of activating transcription factor 6 (ATF6) remained unchanged after incubation with $\mathrm{H}_{2} \mathrm{O}_{2}$. The mechanisms by which the three branches of UPR can be specifically regulated by oxidative stress are currently unresolved and need further investigations.
\end{abstract}

(C) 2014 Elsevier Inc. All rights reserved.

\section{Introduction}

Oxidative stress is due to an imbalance between free radical production and antioxidant capacity of the cell. Mitochondria produce reactive oxygen species (ROS) like superoxide, which is converted into hydrogen peroxide $\left(\mathrm{H}_{2} \mathrm{O}_{2}\right)$ by the reaction catalyzed by superoxide dismutase (SOD). ROS are recognized as signaling molecules regulating physiological and pathological events [1]. Nowadays, endoplasmic reticulum (ER) appears to be a key player in the integration and sensing oxidative signals [2].

ER is a vast membranous network surrounding the nucleus. This organelle provides an oxidizing and high calcium environment where most secreted and membrane proteins are folded [3]. Increasing protein load relative to the folding capacity of the ER leads to accumulation of unfolded proteins, a condition known as ER stress. To cope with this stress, eukaryotic cells have developed an adaptive response called the unfolded protein response (UPR). Unfolded proteins are sensed by three ER transmembrane proteins: inositol-requiring $1 \alpha$ (IRE1 $\alpha$ ), double-stranded RNA-dependent protein kinase (PKR)-like ER kinase (PERK) and activating

\footnotetext{
* Corresponding author. Address: Place Pierre de Coubertin 1, bte L8.10.01, 1348 Louvain-la-Neuve, Belgium. Fax: +32 10472093.

E-mail address: marc.francaux@uclouvain.be (M. Francaux).
}

transcription factor 6 (ATF6). Under unstressed conditions, each of these ER stress sensors is maintained in an inactive state through binding with the protein chaperone binding immunoglobulin protein (BiP). Upon ER stress, $\mathrm{BiP}$ is released, leading to activation of the three sensors and downstream signaling. UPR pathways rapidly inhibit protein synthesis through the phosphorylation of eukaryotic translation-initiation factor $2 \alpha$ (eIF2 $\alpha$ ). This step is followed by a transcriptional upregulation of specific genes coding for proteins implicated in folding, transport and ER-associated degradation (ERAD). If these adaptive responses fail to restore ER homeostasis, an apoptotic response mediated by C/EBP homologous (CHOP) is induced [3].

High concentrations in lipids activate ER stress in various organs like pancreas, liver and adipose tissue [4,5], but also in C2C12 myogenic cells and skeletal muscle of mice [6,7]. In human muscle, ER stress has been observed in sporadic inclusion body myositis, polymyositis, and type 2 diabetes [8,9]. The mechanisms triggering ER stress in muscle cells are still incompletely resolved. Recent studies have shown physical and biochemical interactions between mitochondria and ER [10]. On the one hand, ER and mitochondria are physically associated at the level of a sub-compartment called mitochondria-associated ER membrane (MAM). On the other hand, calcium and ROS are key molecules involved in the communication between mitochondria and ER. For example, 
mitochondrial ROS can target ER-based calcium channels leading to calcium release from the ER to the cytosol. The perturbation of ER calcium homeostasis disrupts protein folding and induces ER stress [10]. It has been shown that oxidative stress induces ER stress in murine fibrosarcoma cells (L929), murine mesencephalic cells (MN9D), human retinal pigment epithelium (RPE) cells, Chinese hamster ovary (CHO) cells, HeLa cells and heart cells (H9c2) [11-15]. However, the pattern of UPR activation seems dependent on cell types. In HeLa cells, $\mathrm{H}_{2} \mathrm{O}_{2}$ activates the three UPR pathways [15] whereas in $\mathrm{L} 929$ cells, $\mathrm{H}_{2} \mathrm{O}_{2}$ activates the PERK pathway but not the IRE1 pathway [11].

Because muscle cells are great ROS providers [16], oxidative stress is a potential regulator of ER stress in these cells. Therefore, the purpose of this study was to investigate whether oxidative stress could induce ER stress in the C2C12 myogenic cell line and to identify which signaling pathways of UPR are specifically activated.

\section{Materials and methods}

\subsection{Cell culture}

C2C12 mouse myoblasts (ATCC, USA) were cultured at $37{ }^{\circ} \mathrm{C}$ in a humidified incubator containing $5 \% \mathrm{CO}_{2}$. Cells were seeded in $8.8 \mathrm{~cm}^{2}$ culture dishes (Nunc, Belgium) and grown in a high glucose $(4.5 \mathrm{~g} / \mathrm{L})$ Dulbeccos's Modified Eagle Medium (DMEM, Life Technologies, USA) supplemented with $10 \%(\mathrm{v} / \mathrm{v})$ foetal bovine serum, $100 \mathrm{U} / \mathrm{ml}$ penicillin and $100 \mu \mathrm{g} / \mathrm{ml}$ streptomycin (Life Technologies). When cells reached confluence $(48 \mathrm{~h})$, medium was replaced by a differentiation medium containing DMEM, 2\% (v/v) horse serum (Lonza, Belgium), $100 \mathrm{U} / \mathrm{ml}$ penicillin and $100 \mu \mathrm{g} / \mathrm{ml}$ streptomycin. After $96 \mathrm{~h}$ of differentiation, $200 \mu \mathrm{M}$ hydrogen peroxide (Sigma-Aldrich, Belgium) or $1 \mu \mathrm{M}$ thapsigargin (Tocris Bioscience, UK) or appropriate solvent in control condition (i.e., water for hydrogen peroxide and DMSO for thapsigargin) was added to the dishes. Cells were harvested after 4 or $17 \mathrm{~h}$.

\subsection{Western blotting}

Cells were lysed in ice-cold and $\mathrm{pH} 7.0$ lysis buffer containing $20 \mathrm{mM}$ Tris, $270 \mathrm{mM}$ sucrose, $5 \mathrm{mM}$ EGTA, $1 \mathrm{mM}$ EDTA, $1 \mathrm{mM}$ sodium orthovanadate, $50 \mathrm{mM} \beta$-glyverophosphate, $5 \mathrm{mM}$ sodium pyrophosphate, $50 \mathrm{mM}$ sodium fluoride, $1 \mathrm{mM}$ DTT (1,4-dithiothreitol), $0.1 \%(\mathrm{v} / \mathrm{v})$ Triton $\mathrm{X}-100$ and $10 \%$ protease inhibitor cocktail (Roche Applied Science, Belgium). The homogenates were then centrifuged at $10,000 \mathrm{~g}$ for $10 \mathrm{~min}$, at $4{ }^{\circ} \mathrm{C}$. Protein concentration was determined using the Detergent Compatible (DC) protein assay kit (Bio-Rad Laboratories, Belgium). Cell lysates were separated by SDS/PAGE and transferred to polyvinylidene fluoride (PVDF) membrane (GE Healthcare, Belgium). Membranes were blocked for $1 \mathrm{~h}$ in a Blotto solution containing Tris-buffered saline with $0.1 \%(\mathrm{v} / \mathrm{v})$ Tween 20 (TBST) with $5 \%(\mathrm{w} / \mathrm{v})$ non-fat dried milk. Then, membranes were incubated overnight at $4{ }^{\circ} \mathrm{C}$ with the following primary antibodies: eukaryotic elongation factor 2 (eEF2), $\mathrm{BiP}$, IRE $1 \alpha$, protein disulfide isomerase (PDI), phosphorylatedeIF2 $\alpha$ (Ser51), phosphorylated-JNK (Thr183/Tyr185). All primary antibodies were from Cell Signaling Technology (The Netherlands). Then membranes were incubated for $1 \mathrm{~h}$ at room temperature with a secondary antibody. Proteins were finally detected using Enhanced Chemiluminescence (ECL) Western blotting Detection System Plus (GE Healthcare). The films were then scanned on an ImageScanner using the Labscan software and quantified with the Image Master 1D Image Analysis Software (GE Healthcare). All results were normalized to eEF2 protein and finally expressed relatively to the control condition.

\subsection{RNA extraction and quantitative real-time $P C R$}

Total RNA extraction from cells was done with Trizol (Life Technologies), according to the manufacturer's instructions. The RNA quality was assessed by $1.5 \%(\mathrm{w} / \mathrm{v})$ agarose gel electrophoresis, while the quantity and purity were measured by NanoDrop ${ }^{\circledR}$ spectrophotometer (Isogen Life Science, Belgium). Reverse transcription was performed with iScript cDNA synthesis kit (Bio-Rad) from $1 \mu \mathrm{g}$ total RNA. Real time PCR experiments were done on a MyIQ2 thermocycler (Bio-Rad). Samples were analyzed in duplicate in $10 \mu \mathrm{l}$ reaction volume containing $4.8 \mu \mathrm{l}$ IQSybrGreen SuperMix (Bio-Rad), $0.1 \mu \mathrm{l}$ of each primer (100 nM final concentration) and $5 \mu \mathrm{l}$ of cDNA. Primers sequences are reported in Table 1 . Melting curves were systematically analyzed to ensure the specificity of the amplification process. Relative quantities were calculated with the standard curve method. Target genes were normalized using three reference genes according to the geNorm analysis [17] and finally expressed relatively to the control group. The reference genes were cyclophilin (CPHN), glyceraldehyde-3-phosphate dehydrogenase (GAPDH) and beta-2-microglobulin (B2M3).

\subsection{Plasmids and cell transfection}

ATF6 transcriptional activity has been detected with Luciferase reporter genes. p5xATF6-GL3 plasmid (Addgene plasmid 11976) contains five repeats of the ATF6 binding site cloned into a minimal promoter preceding the firefly luciferase gene [18]. Renilla plasmid was used to normalize transfection efficiency. Plasmids were amplified in XL1-Blue (Stratagene, USA) and purified with the NucleoBond Xtra Maxi Plus Kit (Macherey-Nagel, Belgium). C2C12 myoblasts were co-transfected (Amaxa Nucleofector ${ }^{\mathrm{TM}}$ Technology, Lonza) at 50-60\% confluence according to the manufacturer's instructions. C2C12 myoblasts $\left(1.10^{6}\right)$ were suspended in $100 \mu \mathrm{l}$ of mouse neuron Nucleofector solution (Lonza) with $2.5 \mu \mathrm{g}$ of p5xATF6-GL3 and $2.5 \mu \mathrm{g}$ of Renilla plasmid. Then, cells were nucleofected and cultivated as described above. After appropriate treatment, cells were lysed with Passive Lysis Buffer (Promega, The Netherlands) and assayed for firefly and Renilla luciferase activities using the Dual Luciferase Reporter Assay System (Promega). Firefly luciferase activity was reported to Renilla luciferase activity.

\subsection{Statistical analysis}

All results were expressed relatively to the control group and are presented as means \pm SEM. Three independent cultures were used. In each culture, the results were generated in duplicate or triplicate. Student test or one-way ANOVA was used to assess statistical differences among means. When appropriate, the Dunnett's

Table 1

Sequences of primers $\left(5^{\prime}-3^{\prime}\right)$.

\begin{tabular}{lll}
\hline Primers & Forward & Reverse \\
\hline BiP & CTATTCCTGCGTCGGTGTGT & GCAAGAACTTGATGTCCTGCT \\
CHOP & CCTGAGGAGAGAGTGTTCCAG & CTCCTGCAGATCCTCATACCA \\
XBP1u & TGAGAACCAGGAGTTAAGAACACGC & CACATAGTCTGAGTGCTGCGG \\
XBP1s & TGAGAACCAGGAGTTAAGAACACGC & CCTGCACCTGCTGCGGAC \\
ATF4 & GAGCTTCCTGAACAGCGAAGTG & TGGCCACCTCCAGATAGTCATC \\
TRB3 & TGTGAGAGGACGAAGCTGGTG & TCGTGGAATGGGTATCTGCC \\
CPHN & CGTCTCCTTCGAGCTGTTTG & CCACCCTGGCACATGAATC \\
GAPDH & TGGAAAGCTGTGGCGTGAT & TGCTTCACCACCTTCTTGAT \\
B2M3 & AAGCCGAACATACTGAACTGC & CGTCTACTGGGATCGAGACAT \\
\hline
\end{tabular}

BiP: binding immunoglobulin protein, CHOP: C/EBP homologous, XBP1u: X-boxbinding protein 1 unspliced, XBP1s: X-box-binding protein 1 spliced, ATF4: activating transcription factor 4, TRB3: tribbles homolog 3, CPHN: cyclophilin, GAPDH: glyceraldehyde-3-phosphate dehydrogenase, B2M3: beta-2-microglobulin. 
method was used as a post hoc analysis. The significance threshold was set for a $P$-value $<0.05$. Statistical significance is indicated in figures with ${ }^{*}(P<0.05)$ and ${ }^{* *}(P<0.01)$.

\section{Results}

\section{1. $\mathrm{H}_{2} \mathrm{O}_{2}$ increases the transcription of UPR-inducible genes}

Transcripts coding for several proteins involved in UPR were regulated upon $\mathrm{H}_{2} \mathrm{O}_{2}$ in $\mathrm{C} 2 \mathrm{C} 12$ myotubes. Four hours after $\mathrm{H}_{2} \mathrm{O}_{2}$ exposure, the spliced form of X-box binding protein 1 (XBP1s) increased by $64 \%(P<0.01)$ whereas the unspliced form $(\mathrm{XBP} 1 \mathrm{u})$ decreased by $23 \%(P=0.021)$ (Fig. $1 \mathrm{~A})$. The two forms of XBP1 were not modified $17 \mathrm{~h}$ after $\mathrm{H}_{2} \mathrm{O}_{2}$ exposure (Fig. 1B). Short- $(4 \mathrm{~h})$ and long-term $(17 \mathrm{~h})$ response to $\mathrm{H}_{2} \mathrm{O}_{2}$ exposure increased the transcript coding for the chaperone $\mathrm{BiP}(65 \%, P<0.01$ and $98 \%$, $P=0.014$; respectively) (Fig. 1). Four hours after $\mathrm{H}_{2} \mathrm{O}_{2}$ treatment, activating transcription factor 4 (ATF4), CHOP and tribbles homo$\log 3$ (TRB3) mRNA increased by $82 \%(P<0.01), 331 \%(P<0.01)$ and $165 \%(P<0.01)$ respectively (Fig. $1 \mathrm{~A})$. A longer period $(17 \mathrm{~h})$ induced a higher increase of ATF4 (141\% $P=0.011)$ CHOP (17-fold, $P<0.01$ ) and TRB3 (34-fold, $P<0.01$ ) mRNA (Fig. 1B).

\section{2. $\mathrm{H}_{2} \mathrm{O}_{2}$ increases the expression of ER stress protein markers}

The protein chaperone BiP was increased $4 \mathrm{~h}(683 \%, P<0.01)$ and $17 \mathrm{~h}$ after $\mathrm{H}_{2} \mathrm{O}_{2}$ exposure $(674 \% P<0.01)$ (Fig. 2). These results confirm those obtained by mRNA analysis (Fig. 1). The phosphorylation state of eIF2 $\alpha$ increased 5-fold $(P=0.02) 4$ h after $\mathrm{H}_{2} \mathrm{O}_{2}$ exposure and was maintained until $17 \mathrm{~h}(336 \%, P<0.01)$. The protein expression of IRE1 $\alpha$ did not change $4 \mathrm{~h}$ after $\mathrm{H}_{2} \mathrm{O}_{2}$ exposure whereas it increased by almost 8 -fold $(P<0.01)$ after 17 h. Finally, PDI protein and the phosphorylation state of JNK were not modified by $\mathrm{H}_{2} \mathrm{O}_{2}$ (Fig. 2).

\section{3. $\mathrm{H}_{2} \mathrm{O}_{2}$ does not activate the ATF6 pathway}

The activation of the ATF6 branch of UPR was assessed by measuring the transcriptional activity of this protein. Four hours and $17 \mathrm{~h}$ after $\mathrm{H}_{2} \mathrm{O}_{2}$ exposure, the transcriptional activity of ATF6 did not change (Fig. 3). In contrast, it was increased by 2 -fold $(P<0.01)$ after $4 \mathrm{~h}$ thapsigargin treatment and by 24 -fold $(P<0.01)$ after $17 \mathrm{~h}$ (Fig. $3 \mathrm{~A}$ and $\mathrm{B})$.

\section{Discussion}

Muscle cells are highly exposed to oxidant molecules. In this context, detection and response to oxidative stress is critical for cell survival. In this study, we show that ER of $\mathrm{C} 2 \mathrm{C} 12$ myotubes senses and responds to oxidative stress. Indeed, $\mathrm{H}_{2} \mathrm{O}_{2}$ treatment activates UPR and increases the level of $\mathrm{BiP}$, a well-recognized marker of ER stress [19]. Due to its diffusion capacity across cell membranes, $\mathrm{H}_{2} \mathrm{O}_{2}$ has been widely used as a model of oxidative stress [1]. Nevertheless, the highly reactive nature of ROS implicates a rapid disappearance of the stress inducer. Gülden et al. (2010) showed that $\mathrm{H}_{2} \mathrm{O}_{2}(200 \mu \mathrm{M})$ was almost completely eliminated from the culture medium of C6 glioma cells after $1 \mathrm{~h} \mathrm{[20].}$ In this study, we decided to investigate a short- $(4 \mathrm{~h})$ and a longterm $(17 \mathrm{~h})$ response after an oxidative stress induced by $200 \mu \mathrm{M}$ $\mathrm{H}_{2} \mathrm{O}_{2}$. Preliminary experiments (data not shown) and results from the literature [21] led us to choose this concentration because it was the best compromise between cell survival and activation of UPR.

IRE1 pathway is the only common branch of UPR between lower eukaryotes and metazoans [22]. When unfolded proteins accumulate into ER, BiP dissociates from IRE1 $\alpha$ leading to its homodimerization and trans-autophosphorylation that in turn, activates its kinase and endoribonuclease (RNAse) domains. IRE1 RNAse cleaves an intron from XBP1 mRNA, which induces a translational frame shift. The isoform resulting from XBP1s mRNA translation is a potent transcription factor that binds to the consensus mammalian ER stress response element (ERSE) [3]. Consequently, the spliced form of XBP1 mRNA (XBP1s) is a proximal and specific marker of the IRE1 pathway. Our results showed an increase of XBP1s after $\mathrm{H}_{2} \mathrm{O}_{2}$ exposure as well as a decrease of the unspliced form giving arguments for an activation of the IRE1 branch of UPR.

Our results confirm a recent study showing an activation of IRE1 by $\mathrm{H}_{2} \mathrm{O}_{2}$ in HeLa cells [15] but not those reported by Xue et al. (2005) who did not observe any change of XBP1s upon $\mathrm{H}_{2} \mathrm{O}_{2}$ treatment (1 mM for 1-8 h) in L929 fibroblasts [12]. In the latter study, XBP1s mRNA was measured by Northern blot, a technique possibly not sensitive enough to detect the slight (64\%), but significant increase that we observed.

In response to ER stress, activated IRE1 $\alpha$ recruits TRAF2 (tumornecrosis factor- $\alpha$-receptor-associated factor 2 ). This complex induces the phosphorylation of JNK linking ER stress to inflammation pathways [23]. In our study, we showed an activation of the IRE1 $\alpha$ pathway but no change was observed in the
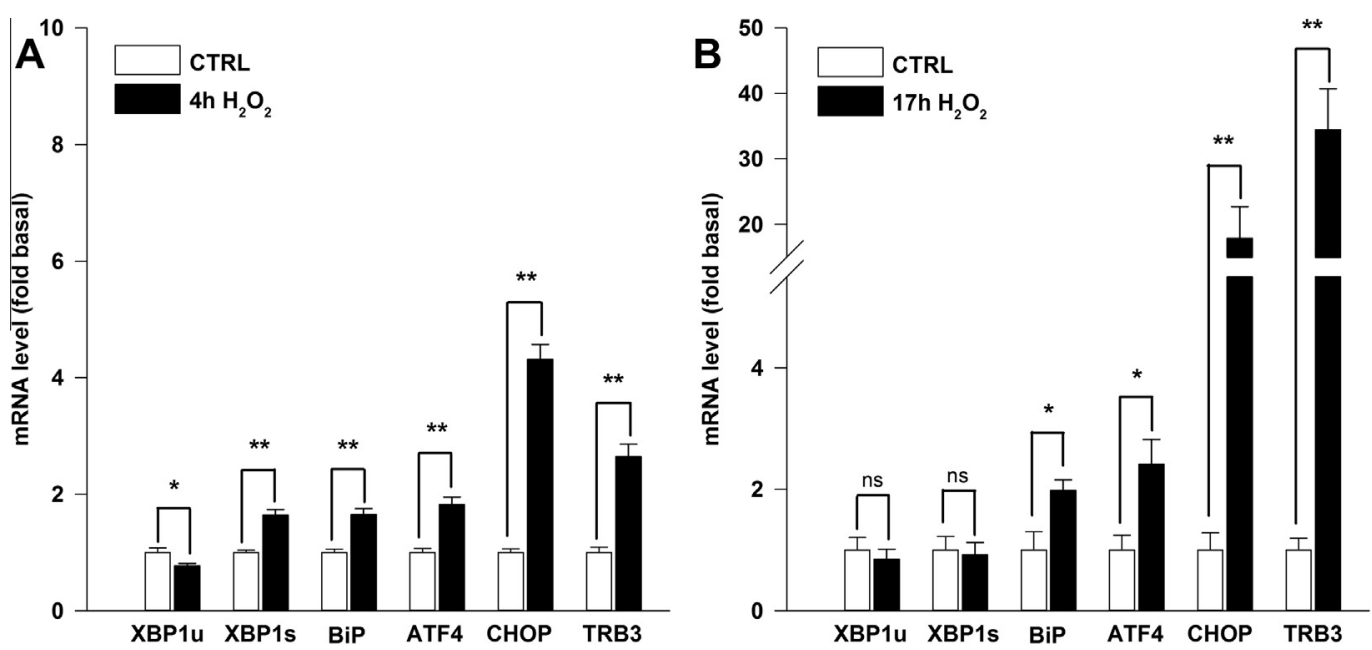

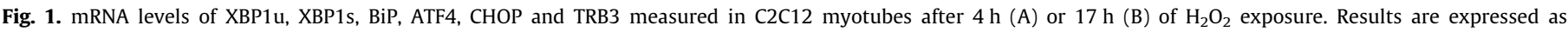
means \pm SEM $(n=3)$; ns, not-significant $(P \geqslant 0.05) ;{ }^{*} P<0.05 ;{ }^{* *} P<0.01$. 

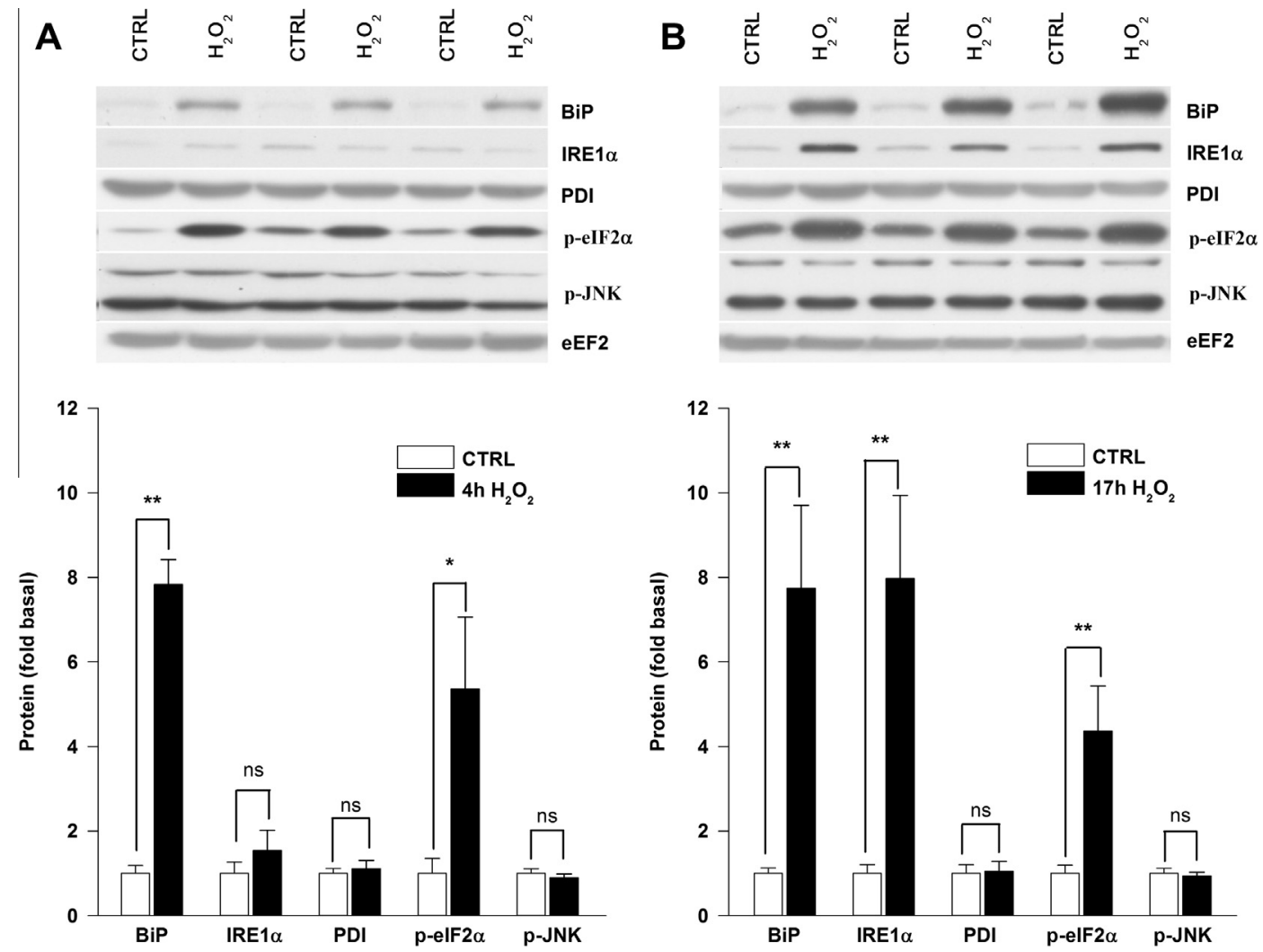

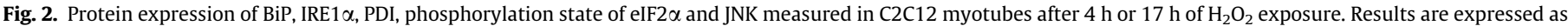
means \pm SEM $(n=3)$; ns, not-significant $(P \geqslant 0.05) ;{ }^{*} P<0.05 ;{ }^{* *} P<0.01$.
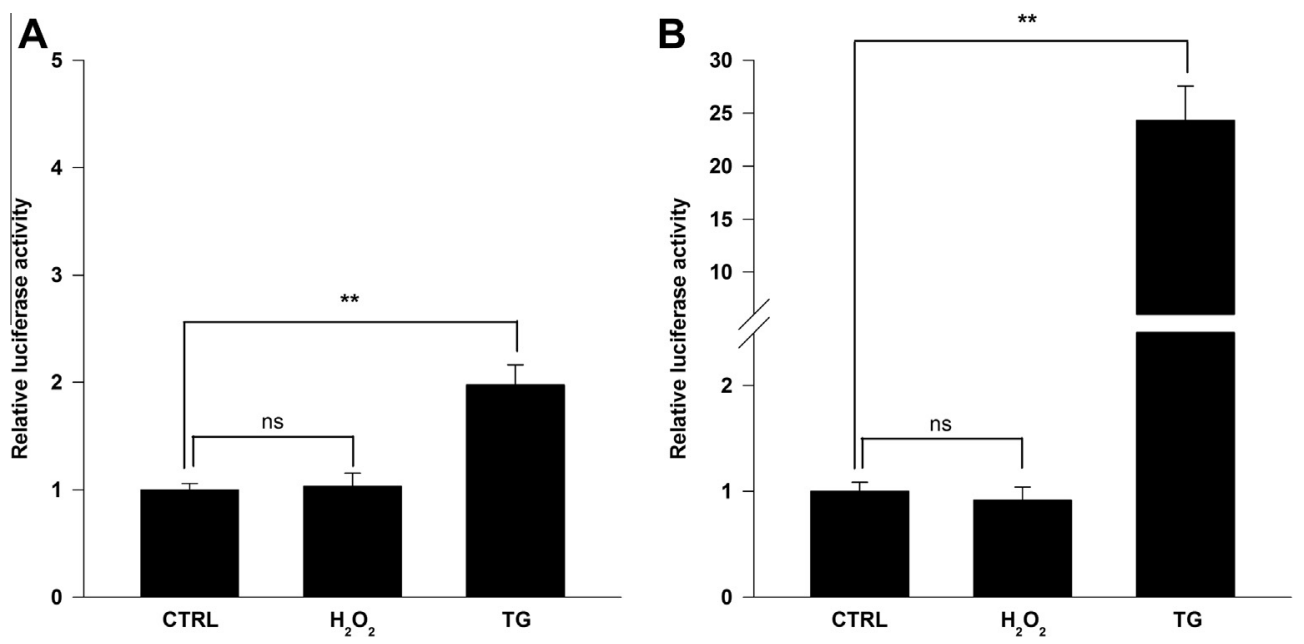

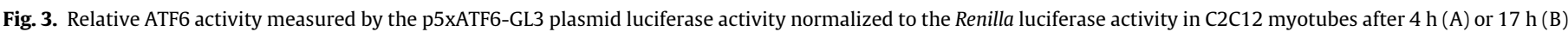
of $\mathrm{H}_{2} \mathrm{O}_{2}$ exposure. Results are expressed as means \pm SEM $(n=3)$; ns, not-significant $(P \geqslant 0.05) ;{ }^{*} P<0.05 ;{ }^{* *} P<0.01$.

phosphorylation state of JNK. This inconsistent result could be explained by three hypotheses: (1) we missed a rapid and transient phosphorylation of JNK that could occur before $4 \mathrm{~h}$; (2) the activation of the IRE1 pathway is too weak to induce JNK phosphorylation. Indeed, XBP1s, a direct marker of IRE1 pathway, increased slightly in comparison to others UPR markers; (3) IRE1 mediatedJNK activation is not present in $\mathrm{C} 2 \mathrm{C} 12$ myotubes. To the best of our knowledge, this pathway has only been demonstrated with pharmacological inducers in liver and pancreatic cells [4,23].

The most immediate response to ER stress is the translational inhibition of protein synthesis. Upon ER stress, PERK homodimerizes to promote its trans-autophosphorylation. The activation of PERK induces the phosphorylation of eIF2 $\alpha$, which inhibits global translation while activating selective translation [24]. In agreement with previous results obtained in other cell types [11,12], we observed that $\mathrm{H}_{2} \mathrm{O}_{2}$ induced eIF $2 \alpha$ phosphorylation in $\mathrm{C} 2 \mathrm{C} 12$ myotubes. However, we may not exclude that eIF2 $\alpha$ could be phosphorylated independently of PERK upon oxidative stress. Four different kinases are known to phosphorylate eIF2 $\alpha$ : PERK, general control non repressed 2 kinase (GCN2), hemeregulated inhibitor kinase (HRI) and interferon-induced doublestranded RNA-dependent protein kinase (PKR). The kinase that 
phosphorylates eIF2 $\alpha$ under oxidative stress is still under debate. Some authors suggested the existence of another eIF2 $\alpha$-kinase specifically induced by oxidative stress [25,26]. Recently, a higher phosphorylation state of PERK was reported upon $\mathrm{H}_{2} \mathrm{O}_{2}$ exposure in HeLa cells but on the opposite, in L929 fibroblasts, other authors reported, no change in PERK phosphorylation state while the phosphorylation state of eIF $2 \alpha$ was increased $[11,15]$. Consequently, eIF2 $\alpha$ phosphorylation induced by $\mathrm{H}_{2} \mathrm{O}_{2}$ is possibly mediated by PERK but we may not exclude a contribution of another kinase.

ATF4 transcript is the most investigated UPR downstream effector translated under eIF2 $\alpha$ phosphorylation. This transcription factor upregulates $\mathrm{CHOP}$, the main mediator of ER-mediated apoptosis [27]. Furthermore, ATF4 cooperates with CHOP to induce the transcription of TRB3 [28]. Consistently with the activation of the PERK branch of UPR, we showed that the mRNA levels of ATF4, CHOP and TRB3 increased after $\mathrm{H}_{2} \mathrm{O}_{2}$ exposure in $\mathrm{C} 2 \mathrm{C} 12$ myotubes.

The ER lumen provides an oxidizing environment, which allows the formation of disulfide bonds. At the end of these oxidation reactions, the electrons are finally transferred to oxygen to form $\mathrm{H}_{2} \mathrm{O}_{2}$ inside ER. Therefore, a higher folding rate increases the production of $\mathrm{H}_{2} \mathrm{O}_{2}$ [3], which subsequently can activate ER stress and UPR as shown in the present study. On the opposite, ER stress also regulates antioxidant defences [26]. For example, the PERK pathway activates the transcription of glutathione S-transferase subunits favoring the redox buffer capacity of ER [29]. The activation of the PERK branch after $\mathrm{H}_{2} \mathrm{O}_{2}$ exposure that we observed is compatible with the idea that ER has the capacity of sensing oxidative environment and to trigger antioxidant response.

The third branch of UPR is initiated by the translocation of ATF6 to the Golgi apparatus where it is cleaved by two proteases. The proteolysis releases a fragment containing a basic region and leucine zipper (bZIP) domain, which migrates to the nucleus, binds to ERSE and induces the transcription of UPR-inducible genes [3]. Activation of ATF6 can be assessed by measuring BiP dissociation, ATF6 translocation, ATF6 cleavage or ATF6 transcriptional activity. The last strategy, used in our experiments, is recognized as a very sensitive method [30]. The lack of changes in the ATF6 transcriptional activity reported in the present study provides evidence against the activation of the ATF6 branch of UPR by $\mathrm{H}_{2} \mathrm{O}_{2}$ in C2C12 myotubes. This is an apparent contradiction with the upregulation of the cleavage of ATF6 found in HeLa cells after $\mathrm{H}_{2} \mathrm{O}_{2}$ exposure [15]. Therefore, in our study, we may not rule out a cleavage of ATF6 without changing its transcriptional activity.

In conclusion, ER of $\mathrm{C} 2 \mathrm{C} 12$ myotubes appears to be able to sense and respond to oxidative stress. Nevertheless, $\mathrm{H}_{2} \mathrm{O}_{2}$-induced oxidative stress does not activate the three branches of UPR to the same extent. The downstream effectors of PERK i.e. eIF2 $\alpha$, ATF4, CHOP and TRB3 are highly responsive to oxidative stress. The IRE1 pathway is slightly activated whereas the transcriptional activity of ATF6 pathway is not modified. The mechanisms by which branches of UPR can be specifically activated by oxidative stress are currently unresolved and need further investigations.

\section{Acknowledgment}

This study was granted by the Fonds spéciaux de Recherche (FSR) of the Université catholique de Louvain.

\section{References}

[1] E.A. Veal, A.M. Day, B.A. Morgan, Hydrogen peroxide sensing and signaling, Mol. Cell 26 (2007) 1-14.

[2] J.D. Malhotra, R.J. Kaufman, Endoplasmic reticulum stress and oxidative stress: a vicious cycle or a double-edged sword?, Antioxid Redox Signal. 9 (2007) 2277-2293.
[3] K. Zhang, R.J. Kaufman, From endoplasmic-reticulum stress to the inflammatory response, Nature 454 (2008) 455-462.

[4] U. Ozcan, Q. Cao, E. Yilmaz, A.H. Lee, N.N. Iwakoshi, E. Ozdelen, G. Tuncman, C. Gorgun, L.H. Glimcher, G.S. Hotamisligil, Endoplasmic reticulum stress links obesity, insulin action, and type 2 diabetes, Science 306 (2004) 457-461.

[5] D.R. Laybutt, A.M. Preston, M.C. Akerfeldt, J.G. Kench, A.K. Busch, A.V. Biankin, T.J. Biden, Endoplasmic reticulum stress contributes to beta cell apoptosis in type 2 diabetes, Diabetologia 50 (2007) 752-763.

[6] N. Pierre, L. Deldicque, C. Barbe, D. Naslain, P.D. Cani, M. Francaux, Toll-like receptor 4 knockout mice are protected against endoplasmic reticulum stress induced by a high-fat diet, PLoS One 8 (2013) e65061.

[7] L. Deldicque, P.D. Cani, A. Philp, J.M. Raymackers, P.J. Meakin, M.L. Ashford, N.M. Delzenne, M. Francaux, K. Baar, The unfolded protein response is activated in skeletal muscle by high-fat feeding: potential role in the downregulation of protein synthesis, Am. J. Physiol. Endocrinol. Metab. 299 (2010) E695-E705.

[8] G. Vattemi, W.K. Engel, J. McFerrin, V. Askanas, Endoplasmic reticulum stress and unfolded protein response in inclusion body myositis muscle, Am. J. Pathol. 164 (2004) 1-7.

[9] H.J. Koh, T. Toyoda, M.M. Didesch, M.Y. Lee, M.W. Sleeman, R.N. Kulkarni, N. Musi, M.F. Hirshman, L.J. Goodyear, Tribbles 3 mediates endoplasmic reticulum stress-induced insulin resistance in skeletal muscle, Nat. Commun. 4 (2013) 1871.

[10] G. Csordas, G. Hajnoczky, SR/ER-mitochondrial local communication: calcium and ROS, Biochim. Biophys. Acta 1787 (2009) 1352-1362.

[11] X. Xue, J.H. Piao, A. Nakajima, S. Sakon-Komazawa, Y. Kojima, K. Mori, H. Yagita, K. Okumura, H. Harding, H. Nakano, Tumor necrosis factor alpha (TNFalpha) induces the unfolded protein response (UPR) in a reactive oxygen species (ROS)-dependent fashion, and the UPR counteracts ROS accumulation by TNFalpha, J. Biol. Chem. 280 (2005) 33917-33925.

[12] W.A. Holtz, J.M. Turetzky, Y.J. Jong, K.L. O’Malley, Oxidative stress-triggered unfolded protein response is upstream of intrinsic cell death evoked by parkinsonian mimetics, J. Neurochem. 99 (2006) 54-69.

[13] S. He, J. Yaung, Y.H. Kim, E. Barron, S.J. Ryan, D.R. Hinton, Endoplasmic reticulum stress induced by oxidative stress in retinal pigment epithelial cells, Graefes Arch. Clin. Exp. Ophthalmol. 246 (2008) 677-683.

[14] N.M. Borradaile, K.K. Buhman, L.L. Listenberger, C.J. Magee, E.T. Morimoto, D.S. Ory, J.E. Schaffer, A critical role for eukaryotic elongation factor $1 \mathrm{~A}-1$ in lipotoxic cell death, Mol. Biol. Cell 17 (2006) 770-778.

[15] P. Pallepati, D.A. Averill-Bates, Activation of ER stress and apoptosis by hydrogen peroxide in HeLa cells: protective role of mild heat preconditioning at 40 degrees C, Biochim. Biophys. Acta 2011 (1813) 1987-1999.

[16] E. Barbieri, P. Sestili, Reactive oxygen species in skeletal muscle signaling, J. Signal Transduct. 2012 (2012) 982794.

[17] J. Vandesompele, K. De Preter, F. Pattyn, B. Poppe, N. Van Roy, A. De Paepe, F. Speleman, Accurate normalization of real-time quantitative RT-PCR data by geometric averaging of multiple internal control genes, Genome Biol. 3 (2002). RESEARCH0034.

[18] Y. Wang, J. Shen, N. Arenzana, W. Tirasophon, R.J. Kaufman, R. Prywes, Activation of ATF6 and an ATF6 DNA binding site by the endoplasmic reticulum stress response, J. Biol. Chem. 275 (2000) 27013-27020.

[19] A.S. Lee, The ER chaperone and signaling regulator GRP78/BiP as a monitor of endoplasmic reticulum stress, Methods 35 (2005) 373-381.

[20] M. Gulden, A. Jess, J. Kammann, E. Maser, H. Seibert, Cytotoxic potency of H2O2 in cell cultures: impact of cell concentration and exposure time, Free Radical Biol. Med. 49 (2010) 1298-1305.

[21] H. Nishida, H. Ichikawa, T. Konishi, Shengmai-san enhances antioxidant potential in $\mathrm{C} 2 \mathrm{C} 12$ myoblasts through the induction of intracellular glutathione peroxidase, J. Pharmacol. Sci. 105 (2007) 342-352.

[22] P. Walter, D. Ron, The unfolded protein response: from stress pathway to homeostatic regulation, Science 334 (2011) 1081-1086.

[23] F. Urano, X. Wang, A. Bertolotti, Y. Zhang, P. Chung, H.P. Harding, D. Ron, Coupling of stress in the ER to activation of JNK protein kinases by transmembrane protein kinase IRE1, Science 287 (2000) 664-666.

[24] P.D. Lu, H.P. Harding, D. Ron, Translation reinitiation at alternative open reading frames regulates gene expression in an integrated stress response, J. Cell Biol. 167 (2004) 27-33.

[25] D. Ron, Translational control in the endoplasmic reticulum stress response, J. Clin. Investig. 110 (2002) 1383-1388.

[26] H.P. Harding, Y. Zhang, H. Zeng, I. Novoa, P.D. Lu, M. Calfon, N. Sadri, C. Yun, B. Popko, R. Paules, D.F. Stojdl, J.C. Bell, T. Hettmann, J.M. Leiden, D. Ron, An integrated stress response regulates amino acid metabolism and resistance to oxidative stress, Mol. Cell 11 (2003) 619-633.

[27] J. Wu, R.J. Kaufman, From acute ER stress to physiological roles of the Unfolded Protein Response, Cell Death Differ. 13 (2006) 374-384.

[28] N. Ohoka, S. Yoshii, T. Hattori, K. Onozaki, H. Hayashi, TRB3, a novel ER stressinducible gene, is induced via ATF4-CHOP pathway and is involved in cell death, EMBO J. 24 (2005) 1243-1255.

[29] J.D. Malhotra, R.J. Kaufman, The endoplasmic reticulum and the unfolded protein response, Semin. Cell Dev. Biol. 18 (2007) 716-731.

[30] J. Shen, R. Prywes, ER stress signaling by regulated proteolysis of ATF6, Methods 35 (2005) 382-389. 